Louisiana State University

LSU Digital Commons

Faculty Publications

Department of Physics \& Astronomy

$10-21-2013$

\title{
Phase diagram and magnetocaloric effects in aluminum doped MnNiGe alloys
}

\author{
Abdiel Quetz \\ Southern Illinois University Carbondale \\ Tapas Samanta \\ Southern Illinois University Carbondale \\ Igor Dubenko \\ Southern Illinois University Carbondale \\ Michael J. Kangas \\ Louisiana State University \\ Julia Y. Chan \\ The University of Texas at Dallas
}

See next page for additional authors

Follow this and additional works at: https://digitalcommons.Isu.edu/physics_astronomy_pubs

\section{Recommended Citation}

Quetz, A., Samanta, T., Dubenko, I., Kangas, M., Chan, J., Stadler, S., \& Ali, N. (2013). Phase diagram and magnetocaloric effects in aluminum doped MnNiGe alloys. Journal of Applied Physics, 114 (15)

https://doi.org/10.1063/1.4826260

This Article is brought to you for free and open access by the Department of Physics \& Astronomy at LSU Digital Commons. It has been accepted for inclusion in Faculty Publications by an authorized administrator of LSU Digital Commons. For more information, please contact ir@lsu.edu. 


\section{Authors}

Abdiel Quetz, Tapas Samanta, Igor Dubenko, Michael J. Kangas, Julia Y. Chan, Shane Stadler, and Naushad Ali 


\title{
Southern Illinois University Carbondale OpenSIUC
}

$10-2013$

\section{Phase Diagram and Magnetocaloric Effects in Aluminum Doped MnNiGe Alloys}

\author{
Abdiel Quetz \\ Southern Illinois University Carbondale \\ Tampas Samanta \\ Southern Illinois University Carbondale \\ Igor Dubenko \\ Southern Illinois University Carbondale \\ Michael J. Kangas \\ Julia Y. Chan
}

See next page for additional authors

Follow this and additional works at: http://opensiuc.lib.siu.edu/phys_pubs

(C) 2013 American Institute of Physics

Published in Journal of Applied Physics Vol. 114 No. 153909 (2013) at doi: 10.1063/1.4826260

\section{Recommended Citation}

Quetz, Abdiel, Samanta, Tampas, Dubenko, Igor, Kangas, Michael J., Chan, Julia Y., Stadler, Shane and Ali, Naushad. "Phase Diagram and Magnetocaloric Effects in Aluminum Doped MnNiGe Alloys." (Oct 2013).

This Article is brought to you for free and open access by the Department of Physics at OpenSIUC. It has been accepted for inclusion in Publications by an authorized administrator of OpenSIUC. For more information, please contact opensiuc@lib.siu.edu. 
Authors

Abdiel Quetz, Tampas Samanta, Igor Dubenko, Michael J. Kangas, Julia Y. Chan, Shane Stadler, and Naushad Ali 


\title{
Phase diagram and magnetocaloric effects in aluminum doped MnNiGe alloys
}

\author{
Abdiel Quetz, ${ }^{1}$ Tapas Samanta, ${ }^{1}$ Igor Dubenko, ${ }^{1}$ Michael J. Kangas, ${ }^{2}$ Julia Y. Chan, ${ }^{3}$ \\ Shane Stadler, ${ }^{4}$ and Naushad Ali ${ }^{1}$ \\ ${ }^{1}$ Department of Physics, Southern Illinois University, Carbondale, Illinois 62902, USA \\ ${ }^{2}$ Department of Chemistry, Louisiana State University, Baton Rouge, Louisiana 70803, USA \\ ${ }^{3}$ Department of Chemistry, University of Texas at Dallas, Richardson, Texas 75080, USA \\ ${ }^{4}$ Department of Physics \& Astronomy, Louisiana State University, Baton Rouge, Louisiana 70803, USA
}

(Received 5 July 2013; accepted 4 October 2013; published online 21 October 2013)

\begin{abstract}
The magnetocaloric and thermomagnetic properties of the $\mathrm{MnNiGe}_{1-\mathrm{x}} \mathrm{Al}_{\mathrm{x}}$ system have been studied by temperature-dependent $\mathrm{x}$-ray diffraction, differential scanning calorimetry (DSC), and magnetization measurements. The partial substitution of $\mathrm{Al}$ for $\mathrm{Ge}$ in $\mathrm{MnNiGe}_{1-\mathrm{x}} \mathrm{Al}_{\mathrm{x}}$ results in a first order magnetostructural transition (MST) from a hexagonal ferromagnetic to an orthorhombic antiferromagnetic phase at $186 \mathrm{~K}$ (for $\mathrm{x}=0.09$ ). A large magnetic entropy change of $\Delta \mathrm{S}_{\mathrm{M}}=-17.6 \mathrm{~J} / \mathrm{kg} \mathrm{K}$ for $\Delta \mathrm{H}=5 \mathrm{~T}$ was observed in the vicinity of $\mathrm{T}_{\mathrm{M}}=186 \mathrm{~K}$ for $\mathrm{x}=0.09$. The value is comparable to those of giant magnetocaloric materials such as $\mathrm{Gd}_{5} \mathrm{Si}_{2} \mathrm{Ge}_{2}$, $\mathrm{MnFeP}_{0.45} \mathrm{As}_{0.55}$, and $\mathrm{Ni}_{50} \mathrm{Mn}_{37} \mathrm{Sn}_{13}$. The values of the latent heat $(\mathrm{L}=6.6 \mathrm{~J} / \mathrm{g})$ and corresponding total entropy changes $\left(\Delta \mathrm{S}_{\mathrm{T}}=35 \mathrm{~J} / \mathrm{kg} \mathrm{K}\right)$ have been evaluated for the MST using DSC measurements. Large negative values of $\Delta \mathrm{S}_{\mathrm{M}}$ of -5.8 and $-4.8 \mathrm{~J} / \mathrm{kg} \mathrm{K}$ for $\Delta \mathrm{H}=5 \mathrm{~T}$ in the vicinity of $\mathrm{T}_{\mathrm{C}}$ were observed for $\mathrm{x}=0.09$ and 0.085 , respectively. A concentration-dependent phase diagram of transition temperatures (magnetic, structural, and magnetostructural) has been generated using magnetic, XRD, and DSC data. The role of magnetic and structural changes on transition temperatures is discussed. (C) 2013 AIP Publishing LLC. [http://dx.doi.org/10.1063/1.4826260]
\end{abstract}

\section{INTRODUCTION}

MnNiGe based intermetallic compounds belong to the family of the magnetic materials that undergo magnetostructural transitions (MST) near room temperature. ${ }^{1}$ Such transitions are of great interest from fundamental and technological points of view due to their significant magnetoresponsive behaviors, resulting in unique phenomena such as giant magnetocaloric effects, ${ }^{1-3}$ magnetoresistance, ${ }^{4}$ magnetostriction, ${ }^{5}$ and magnetic shape memory, etc.

Stoichiometric MnNiGe undergoes a first order structural transition (FOT) from a low-temperature phase (LTP), i.e., an orthorhombic TiNiSi-type crystal structure, to a hightemperature hexagonal $\mathrm{Ni}_{2} \mathrm{In}$-type structure at $470 \mathrm{~K}$. Both phases are in paramagnetic states in the vicinity and above the FOT. The low temperature phase is magnetically ordered below $\mathrm{T}_{\mathrm{N}} \sim 346 \mathrm{~K}$ with a spiral antiferromagnetic (AFM) structure. ${ }^{6}$ Recently, it has been found that changes in stoichiometry and chemical composition can drastically change the FOT temperature. In some cases the structural transformation occurs below $\mathrm{T}_{\mathrm{N}}$ of the LTP and therefore results in a first order change of magnetic state of the MnNiGe based compounds. ${ }^{7-10}$ The Mn-Mn distance has been considered as a major factor affecting the crystal phase stability in these compounds. ${ }^{7,8,11}$ However, most studies have considered systems with constricted lattices with respect to the parent compounds. ${ }^{7,8,11}$ In a previous study (see Ref. 12), we show that the expansion of the lattice cell, as observed for $\mathrm{MnNiGe}_{1-\mathrm{x}} \mathrm{Al}_{\mathrm{x}}$, results in the formation of an MST from a hexagonal ferromagnetic to an orthorhombic antiferromagnetic phase at $193 \mathrm{~K}$ and $186 \mathrm{~K}$ for $\mathrm{x}=0.085$ and 0.09 , respectively. The values of the latent heat
(L), corresponding to total entropy changes $\left(\Delta \mathrm{S}_{\mathrm{T}}\right)$ and magnetic-field-induced entropy changes $\left(\Delta \mathrm{S}_{\mathrm{M}}\right)$ in the vicinity of the MST, were found to be $\mathrm{L}=6.6 \mathrm{~J} / \mathrm{g}, \Delta \mathrm{S}_{\mathrm{T}}=35 \mathrm{~J} / \mathrm{kg} \mathrm{K}$, and $\Delta \mathrm{S}_{\mathrm{M}}=17.6 \mathrm{~J} / \mathrm{kg} \mathrm{K}$ (for $\Delta \mathrm{H}=5 \mathrm{~T}$ ), respectively. The magnetocaloric effect (MCE) parameters observed for the $\mathrm{MnNiGe}_{1-\mathrm{x}} \mathrm{Al}_{\mathrm{x}}$ system are comparable to well-known giant magnetocaloric materials such as $\mathrm{Gd}_{5} \mathrm{Si}_{2} \mathrm{Ge}_{2},{ }^{16} \mathrm{Ni}_{50} \mathrm{Mn}_{37} \mathrm{Sn}_{13}{ }^{3}$ and $\mathrm{MnFeP}_{0.45} \mathrm{As}_{0.55}{ }^{2}$ Therefore, a detailed knowledge of the influence of $\mathrm{Al}$ substitution on phase transitions and magnetocaloric effects of MnNiGe are desirable. In the current work, results of the studies of the fractional substitution of $\mathrm{Ge}$ by $\mathrm{Al}$ on the magnetic, magnetocaloric, and structural properties of the $\mathrm{MnNiGe}_{1-\mathrm{x}} \mathrm{Al}_{\mathrm{x}}$ compound with $0<\mathrm{x}<0.20$ along with the magnetic phase diagram are reported.

\section{EXPERIMENTAL TECHNIQUES}

The $\mathrm{MnNiGe}_{1-\mathrm{x}} \mathrm{Al}_{\mathrm{x}}$ aluminum doped samples with $0<\mathrm{x}<0.20$ were arc-melted in an ultra-high purity argon atmosphere using $99.99 \%$ purity elements. The compounds were annealed in high vacuum $\left(\approx 10^{-5}\right.$ Torr $)$ for $96 \mathrm{~h}$ at a temperature of $850^{\circ} \mathrm{C}$. XRD with $\mathrm{Cu} K \alpha$ radiation was implemented to measure the room temperature diffraction patterns, and the Rietveld profile refinement method was employed within the FULLPROF program to obtain the structural properties of the samples. The X-ray diffraction measurements in the temperature interval $(100-370 \mathrm{~K})$ have been done using a single crystal with size $\sim 0.1 \times 0.1 \times 0.1 \mathrm{~mm}$ that was selected from a crushed polycrystalline ingot of $\mathrm{NiMnGe}_{0.91} \mathrm{Al}_{0.09}$ (nominal composition). The crystal was then mounted on a glass fiber with epoxy, coated in vacuum 
grease, and placed on the goniometer of a Nonius Kappa $\mathrm{CCD} \mathrm{X}$-ray diffractometer with a Mo $\mathrm{K} \alpha$ radiation $(\lambda=0.71073 \AA)$ source. All temperature ramp rates were $60 \mathrm{~K} / \mathrm{h}$ to minimize stress on the crystal. For crystal structure determinations, the crystal was held at the target temperature for a minimum of $20 \mathrm{~min}$ to ensure the crystal was equilibrated. XRD data were collected at 370, 296, 200, and $100 \mathrm{~K}$. The crystal structure was solved by direct methods with SIR97 ${ }^{19}$ and refined with SHELXL97. ${ }^{20}$ Lattice parameters as a function of temperature were collected by first warming the crystal to $370 \mathrm{~K}$ and cooling to $100 \mathrm{~K}$. The magnetization measurements were obtained in a temperature interval of 5 to $380 \mathrm{~K}$ at magnetic fields up to $5 \mathrm{~T}$ using a superconducting quantum interference device magnetometer (SQUID by Quantum Design). The differential scanning calorimetry (DSC) measurements were obtained using a DSC 8000 instrument (with a ramp rate of $20 \mathrm{~K} / \mathrm{min}$ during heating and cooling) in the temperature range of $103-573 \mathrm{~K}$. The latent heat (L) was estimated from the endothermic peak of the heat flow curve using $L=\int_{T_{s}}^{T_{f}} \frac{d Q}{d T} d T$, where $\frac{d Q}{d T}$ is the change of heat flow with respect to temperature, and $T_{s}$ and $T_{f}$ are the initial and final temperatures of the magnetostructural phase transitions on heating, respectively.

\section{RESULTS AND DISCUSSION}

The orthorhombic TiNiSi-type and hexagonal $\mathrm{Ni}_{2}$ In-type crystal structures were identified from XRD patterns of the $\mathrm{MnNiGe}_{1-\mathrm{x}} \mathrm{Al}_{\mathrm{x}}$ samples at room temperature for the compounds with $\mathrm{x} \leq 0.03$ and $\mathrm{x} \geq 0.5$, respectively (see Figure 1 for representative compounds). As can be seen from Figure 2, the $\mathrm{M}(\mathrm{H})$ curves are characterized by different behaviors depending on $\mathrm{Al}$ concentration. At least two types of $\mathrm{M}(\mathrm{H})$ curves were detected. The compounds with $\mathrm{x} \leq 0.095$ demonstrate a behavior typical for antiferromagnetic ordering with compensated magnetization at zero-field and a "spin-flip"-like transition (SFT) induced by magnetic field. The parent compounds have spiraled AFM structures;

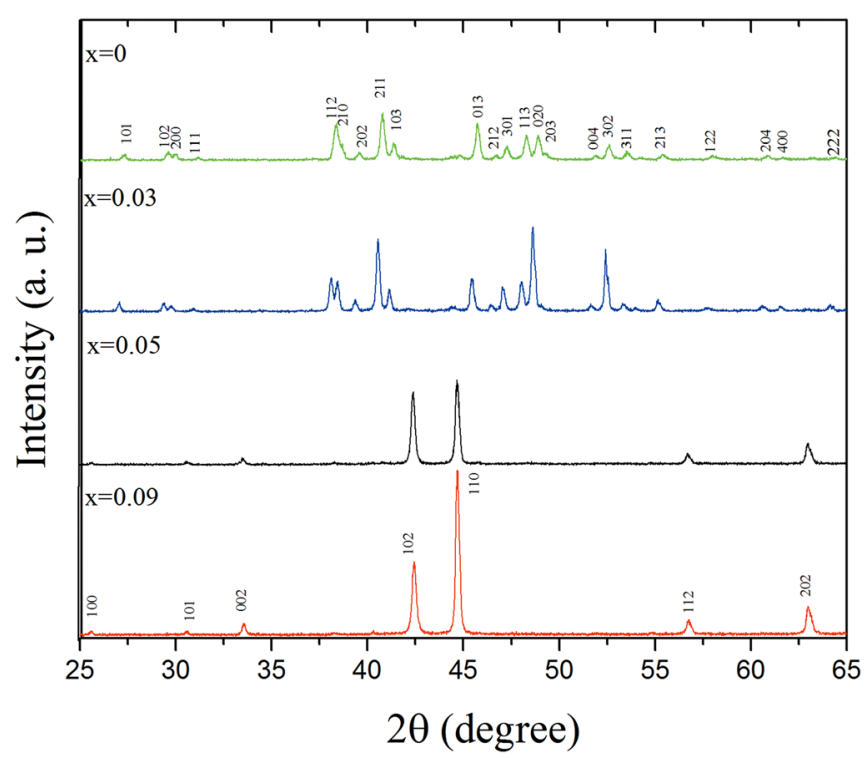

FIG. 1. The XRD patterns of $\mathrm{MnNiGe}_{1-\mathrm{x}} \mathrm{Al}_{\mathrm{x}}$ for different aluminum concentrations $(\mathrm{X})$ at room temperature.

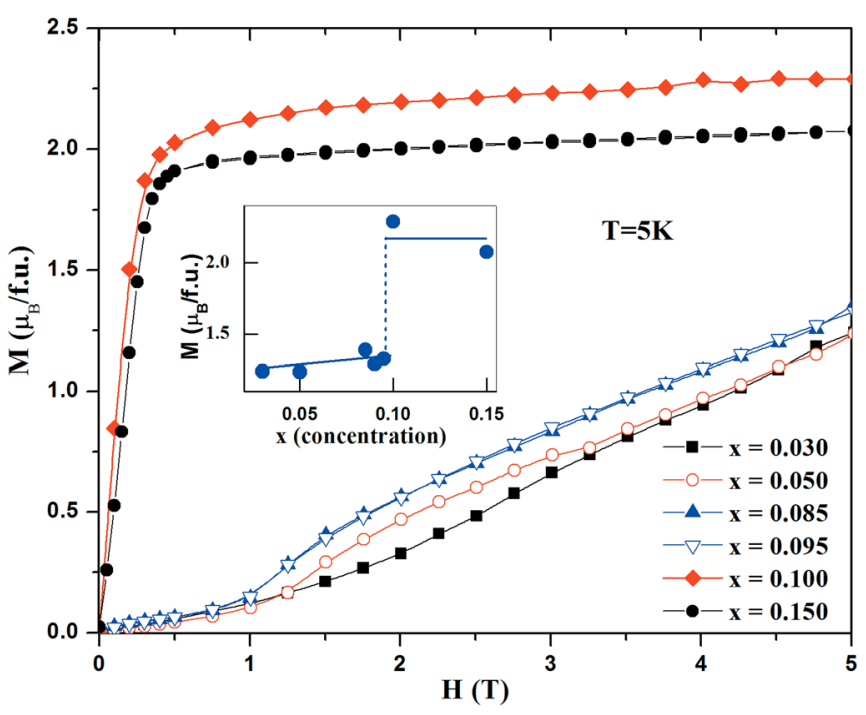

FIG. 2. The $\mathrm{M}(\mathrm{H})$ of $\mathrm{MnNiGe}_{1-\mathrm{x}} \mathrm{Al}_{\mathrm{x}}$ for $0.03<\mathrm{x}<0.150$ at $\mathrm{T}=5 \mathrm{~K}$. Inset: The magnetic moment of $\mathrm{MnNiGe}_{1-\mathrm{x}} \mathrm{Al}_{\mathrm{x}}$ system at $5 \mathrm{~T}$.

therefore, the observed transitions can be associated with a transition from a spiral AFM to a non-collinear state induced by magnetic field. Increasing the $\mathrm{Al}$ concentration results in a decrease in the critical field of the SFT to $1.2 \mathrm{~T}$ for $\mathrm{x}=0.05$, which most likely results from a decrease of the magnetocrystalline anisotropy.

The compounds with $\mathrm{x} \geq 0.1$ show ferromagnetic-like magnetization curves with a magnetic moment $\sim 2.0 \mu_{\mathrm{B}} /$ f.u. at $5 \mathrm{~T}$, an anisotropy field $\mathrm{H}_{\mathrm{A}} \sim 1.5 \mathrm{~T}$, and a magnetic susceptibility $\chi_{\mathrm{o}} \sim 0.2 \mu_{\mathrm{B}} /$ f.u./T at $\mathrm{H}>\mathrm{H}_{\mathrm{A}}$. The relatively large $\chi_{\mathrm{o}}$ detected for the compounds in the ferromagnetic state is evidence of itinerant characteristics of the magnetism. The increase in the magnetization at $5 \mathrm{~T}$ by a factor of 2 indicates a change in the magnetic ordering induced by the $\mathrm{Al}$ (see inset of Figure 2). Thus, the magnetic ground state depends on $\mathrm{Al}$ concentration and changes from AFM to FM ordering at the critical aluminum concentration $\mathrm{x}_{\mathrm{C}} \approx 0.1$.

The temperature dependence of the magnetization measured in applied fields of $0.1 \mathrm{~T}$ and $5 \mathrm{~T}$ is shown in Figure 3.

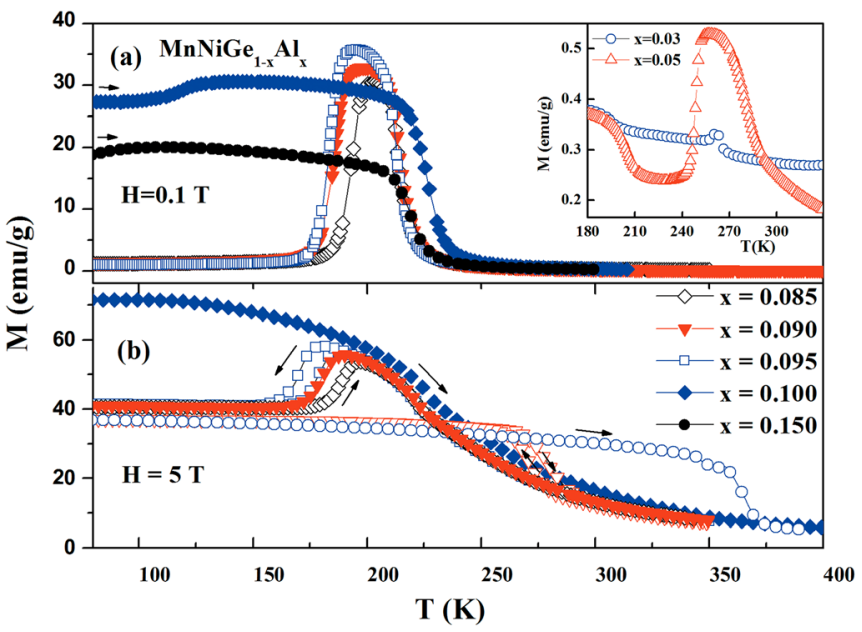

FIG. 3. (a) The $\mathrm{M}(\mathrm{T})$ curves for $\mathrm{MnNiGe}_{1-\mathrm{x}} \mathrm{Al}_{\mathrm{x}}$ obtained for heating cycles at $H=0.1$ T. Inset: $M(T)$ for $x=0.03$ and $x=0.05$, and (b) The $M(T)$ curves obtained at $\mathrm{H}=5 \mathrm{~T}$ for heating and cooling as indicated by the arrows. 


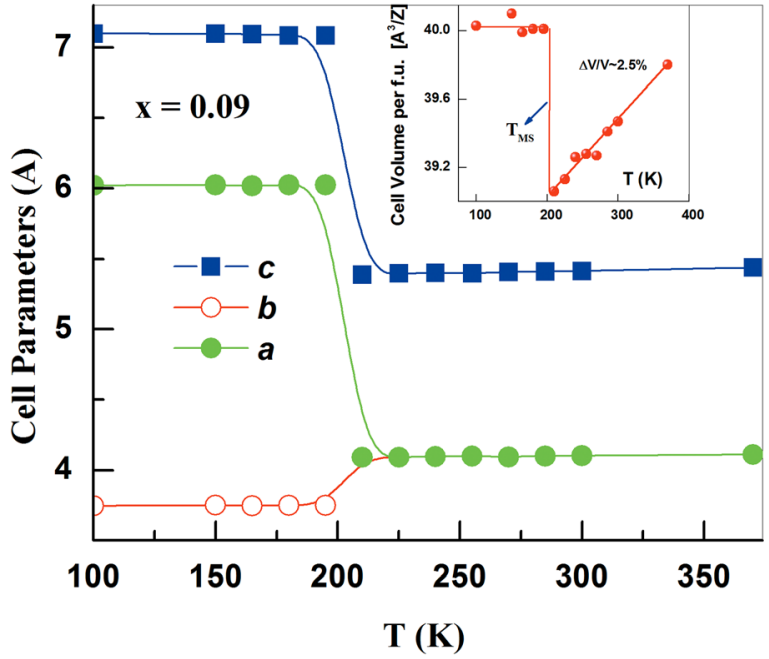

FIG. 4. Temperature dependence of the cell parameters of $\mathrm{MnNiGe}_{0.91} \mathrm{Al}_{0.09}$. Inset: $\mathrm{MnNiGe}_{0.91} \mathrm{Al}_{0.09}$ cell volume with respect to temperature.

The $\mathrm{MnNiGe}_{1-\mathrm{x}} \mathrm{Al}_{\mathrm{x}}$ system exhibits three distinct temperature dependent behavior regimes, depending on $\mathrm{Al}$ concentration. The Ge-rich samples $(x \leq 0.05)$ exhibit a maximum in the $\mathrm{M}(\mathrm{T})$ curves at the $\mathrm{T}=\mathrm{T}_{\mathrm{N}}$ (see inset of Figure 3(a)) and a temperature hysteresis of $\mathrm{M}(\mathrm{T})$ (see Figure 3(b)). Taking into account the AFM-type of magnetization at $5 \mathrm{~K}$ (see Figure 2), and the similar temperature-dependent behavior of the magnetization of the parent $\mathrm{MnNiGe}^{6}$ it is natural to relate the transitions observed for compounds with $\mathrm{x} \leq 0.05$ to a structural martensitic-like transition from a hexagonal AF to an orthorhombic AF structure.

The compounds with $\mathrm{x} \geq 0.1$ show $\mathrm{M}(\mathrm{T})$ curves consistent with ferromagnetic behavior. At least two phase transitions are clearly seen in the $\mathrm{M}(\mathrm{T})$ curves of $\mathrm{MnNiGe}_{1-\mathrm{x}} \mathrm{Al}_{\mathrm{x}}$ with $0.05<\mathrm{x}<0.1$. These are the low temperature transitions with jump-like increases in magnetization at $\mathrm{T}=\mathrm{T}_{\mathrm{MS}}$ with thermal hysteresis, and a high temperature transition to a paramagnetic state at $\mathrm{T}_{\mathrm{C}}$. Considering the magnetization curves $\mathrm{M}(\mathrm{H})$ in the vicinity of the phase transitions, one can conclude that the low and high-temperature transitions are from AF to FM and from FM to PM, respectively.

The temperature-dependent XRD study of the crystal structure of $\mathrm{MnNiGe}_{0.91} \mathrm{Al}_{0.09}$ has been carried out to clarify the nature of the low temperature transitions. As observed in Figure 4, a jump-like change in the cell parameters, as well as an increase in cell volume (see inset of Figure 4), takes place in the vicinity of $T_{M} \sim 200 \mathrm{~K}$. At room temperature, the diffraction pattern was indexed to a hexagonal unit cell (see Table I). Systematic peak absences indicated the space group

TABLE I. Cell parameters of $\mathrm{MnNiGe}_{1-\mathrm{x}} \mathrm{Al}_{\mathrm{x}}$ system at room temperature.

\begin{tabular}{lcccc}
\hline \hline $\mathrm{x}$ & $\mathrm{c}(\AA)$ & $\mathrm{a}(\AA)$ & $\mathrm{c} / \mathrm{a}$ & Volume $(\AA)^{3}$ \\
\hline 0.05 & 5.429 & 4.098 & 1.325 & 78.99 \\
0.07 & 5.428 & 4.099 & 1.324 & 79.00 \\
0.085 & 5.425 & 4.100 & 1.323 & 79.00 \\
0.09 & 5.426 & 4.102 & 1.323 & 78.92 \\
0.1 & 5.425 & 4.108 & 1.321 & 79.30 \\
0.15 & 5.425 & 4.102 & 1.322 & 79.06 \\
\hline \hline
\end{tabular}

TABLE II. Crystallographic parameters of $\mathrm{NiMnGe}_{0.91} \mathrm{Al}_{0.09}$ for $100 \mathrm{~K}$ (orthorhombic), and $296 \mathrm{~K}$ (hexagonal).

\begin{tabular}{lcc}
\hline \hline Compound & $\mathrm{NiMnGe}_{0.91} \mathrm{Al}_{0.09}$ & $\mathrm{NiMnGe}_{0.91} \mathrm{Al}_{0.09}$ \\
\hline Crystal system & Hexagonal & Orthorhombic \\
Space group & $P 6_{3} / m m c$ & Pnma \\
$a(\AA)$ & $4.102(2)$ & $6.015(1)$ \\
$b(\AA)$ & $4.102(2)$ & $3.734(2)$ \\
$c(\AA)$ & $5.416(3)$ & $7.089(2)$ \\
$\mathrm{V}(\AA)^{3}$ & $78.92(7)$ & $159.22(10)$ \\
$\mathrm{Z}$ & 2 & 4 \\
$\mathrm{Refinement}$ & & 0.0227 \\
$\mathrm{R}_{1}$ & 0.0275 & 0.0548 \\
$w_{2}$ & 0.0721 & \\
\hline \hline
\end{tabular}

to be $P 6_{3} / m m c$. In the refinement procedures, the aluminum was initially placed on the germanium site (based on stoichiometry) and the occupancy was refined. Because the refined occupancy of aluminum (8\%) was close to the nominal composition $(9 \%)$, the aluminum was kept on the germanium site and fixed to the nominal value. The structures at $200 \mathrm{~K}$ and $370 \mathrm{~K}$ were consistent with the room temperature polymorph. At $100 \mathrm{~K}$, the crystal structure of $\mathrm{NiMnGe}_{0.91} \mathrm{Al}_{0.09}$ was found to adopt the previously reported ${ }^{6}$ low temperature polymorph of NiMnGe (Pnma). Details of the collection/refinement and atomic positions are provided in Table II for $100 \mathrm{~K}$ and $296 \mathrm{~K}$. Therefore, as confirmed by these temperature-dependent XRD results, the first order, low temperature transitions observed for $\mathrm{MnNiGe}_{1-\mathrm{x}} \mathrm{Al}_{\mathrm{x}}$ with $0.05<\mathrm{x}<0.1$ are magnetostructural transitions. It is also interesting to note that the transitions are accompanied by a giant positive volume anomaly $\Delta \mathrm{V} / \mathrm{V}$ of about $2.5 \%$ (see inset of Figure 4). The first order nature of the phase transitions observed in $\mathrm{MnNiGe}_{1-\mathrm{x}} \mathrm{Al}_{\mathrm{x}} \mathrm{x}<0.1$ has been also confirmed by the temperature hysteresis of heat flow transition peaks obtained from DSC measurements (see Figure 5). The large endothermic/exothermic peaks, observed during heating/cooling cycles, were also observed in previous experiments for MST samples in this system, ${ }^{12}$ and are related

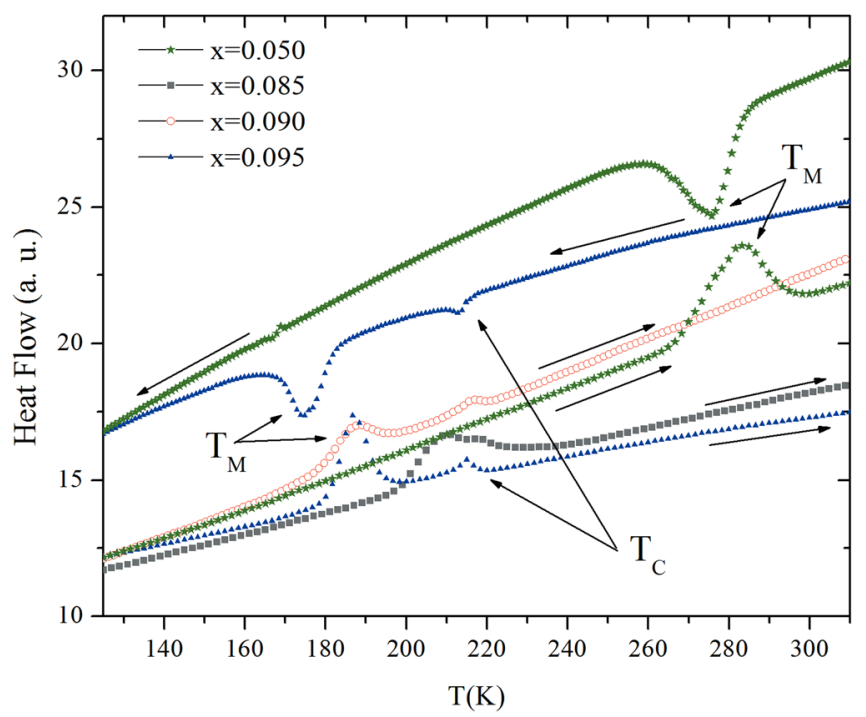

FIG. 5. DSC heat flow curves as a function of temperature for $\mathrm{MnNi}(\mathrm{Ge}, \mathrm{Al})$ obtained for cooling and heating cycles as indicated by the arrows. 
to the latent heat of the first-order magnetostructural transition from the antiferromagnetic TiNiSi-type structure to the ferromagnetic $\mathrm{Ni}_{2}$ In-type structure. The temperature hysteresis of heat flow of about $20 \mathrm{~K}$ between heating and cooling cycles detected from DSC measurements are consistent with magnetization results.

The variations of the phase transition temperatures as a function of $\mathrm{Al}$ concentration are summarized in the (T-x)phase diagram (see Figure 6). An increase in Al content results in an increase of the phase transition temperatures related to the changes in magnetic ordering at $T_{N}$ and $T_{C}$ in the orthorhombic $(0 \leq x \leq 0.03)$ and hexagonal phases $(0.08 \leq x \leq 0.15)$, respectively. The temperatures of the structural transitions $\mathrm{T}_{\mathrm{M}}$ and $\mathrm{T}_{\mathrm{MS}}$ decrease with increasing Al concentration, and abruptly vanish at some critical Al concentration in the interval $0.095<\mathrm{x} \leq 0.10$; as a consequence only the hexagonal phase is present for $x \geq 0.1$.

The concentration of conduction electrons per atom (e/A) and dimensional factors (such as crystal cell parameters, volume, degree of the tetragonal distortions, and c/a), are traceable, experimental factors affecting the phase transitions in magnetic Heusler alloys. ${ }^{13}$ Since Al has fewer valence electrons and a larger metallic radius compared to $\mathrm{Ge}$, the substitution of $\mathrm{Ge}$ with $\mathrm{Al}$ in $\mathrm{MnNiGe}_{1-\mathrm{x}} \mathrm{Al}_{\mathrm{x}}$ up to $\mathrm{x}=0.15$ results in a decrease of about $0.4 \%$ in electronic concentration and an increase of $\sim 0.1 \%$ in cell volume (see Table I). The behavior of the structural transition temperatures is consistent with the results reported in Ref. 14 where a decrease in $\mathrm{T}_{\mathrm{M}}$ of about $210 \mathrm{~K}$ was observed for a $\sim 0.1 \%$ change in e/a.

As shown in the inset of the Figure 6, Al substitution induces a decrease in the c lattice parameter, and a decrease in the degree of hexagonal distortion (c/a-ratio). It has been found from band structure calculations that the free energy of the martensitic phase depends on the c/a ratio. ${ }^{15}$ Thus, based on these results and observed behaviors, it can be concluded that the increase of cell volume of the austenitic phase results in a loss of martensitic phase stability, similar

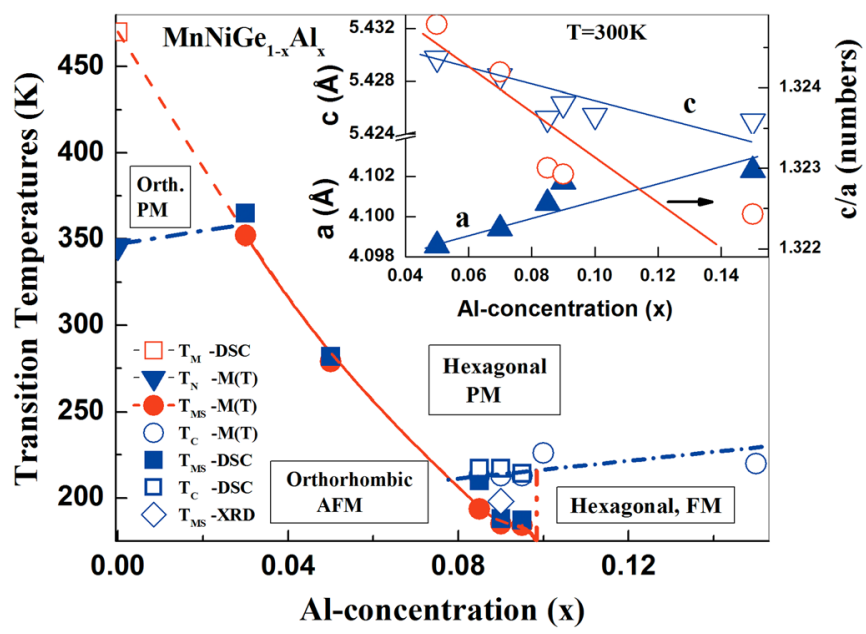

FIG. 6. Temperature of the magnetic $\left(\mathrm{T}_{\mathrm{N}}, \mathrm{T}_{\mathrm{C}}\right)$, structural $\left(\mathrm{T}_{\mathrm{M}}\right)$, and magnetostructural $\left(\mathrm{T}_{\mathrm{MS}}\right)$ transitions with respect to $\mathrm{Al}$ concentration $(\mathrm{x})$ obtained from different types of measurements as labeled. Inset: The concentration dependence of the cell parameters a and $\mathrm{c}$ and the c/a ratio obtained at $\mathrm{T}=300 \mathrm{~K}$ for hexagonal $\mathrm{MnNi}(\mathrm{Ge}, \mathrm{Al})$ compounds. to that observed in the case of the $\mathrm{Ni}_{2} \mathrm{Mn}(\mathrm{Ga}, \mathrm{In})$ system in Ref. 16. Therefore, there is the range of c/a values where the martensitic transformation can be observed. In the case of the $\mathrm{MnNiGe}_{1-\mathrm{x}} \mathrm{Al}_{\mathrm{x}}$ compounds, when $\mathrm{c} / \mathrm{a}>1.323$ the high temperature hexagonal phase is stable for all temperatures.

Two factors affecting the magnetic ordering temperatures $\mathrm{T}_{\mathrm{N}}$ and $\mathrm{T}_{\mathrm{C}}$ for $0 \leq \mathrm{x} \leq 0.03$ and $0.085<\mathrm{x} \leq 0.15$, respectively, can be highlighted based on the results. These are related to the changes in the electron concentration (e/a) and $\mathrm{Mn}-\mathrm{Mn}$ distance as a result of $\mathrm{Al}$ substitution. If the $\mathrm{N}\left(\mathrm{E}_{\mathrm{F}}\right)$ has a positive curvature in the vicinity of $\mathrm{E}_{\mathrm{F}}$, a decrease in e/a results in an increase in $\mathrm{N}\left(\mathrm{E}_{\mathrm{F}}\right)$, and therefore in the net magnetic moment of itinerant electrons (or in the magnetic moment of the magnetic sublattice in the case of $\mathrm{AF}$ ordering) and subsequently in the free energy terms related to exchange interactions, similar to that observed in the case of $\mathrm{Y}(\mathrm{Co}, \mathrm{Al})_{2}$ compounds. ${ }^{17}$ As a result, both $\mathrm{T}_{\mathrm{N}}$ and $\mathrm{T}_{\mathrm{C}}$ increase with Al-concentration in $\mathrm{MnNiGe}_{1-\mathrm{x}} \mathrm{Al}_{\mathrm{x}}$. The $\mathrm{Mn}-\mathrm{Mn}$ distance increases and decreases in-plane and along the c axis, respectively (see inset of Figure 6). Such changes can affect the delicate balance of the positive and negative exchange interactions that account for the antiferromagnetic, spiral-like magnetic structure of the parent compound, and results in an increase of the ordering temperatures of the compounds under consideration. However, taking into account that the $\mathrm{T}_{\mathrm{N}}$ and $\mathrm{T}_{\mathrm{C}}$ lines in the phase diagram (see the blue dot-dashed lines in Fig. 6) are nearly parallel, the first mechanism is preferable. Thus, Al substitution tends to increase the magnetic moment by shifting $\mathrm{E}_{\mathrm{F}}$ toward the maximum of $\mathrm{N}\left(\mathrm{E}_{\mathrm{F}}\right)$, and results in an increase of $\mathrm{T}_{\mathrm{N}}$ and $\mathrm{T}_{\mathrm{C}}$, putting the system into a high magnetization state for $\mathrm{x}>0.90$.

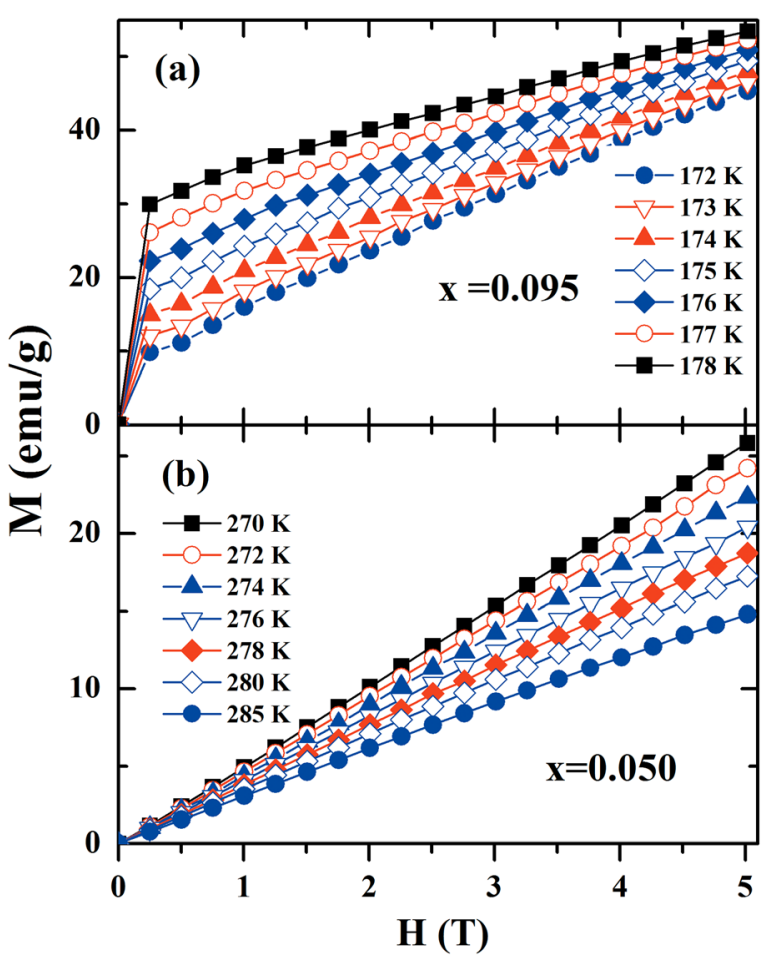

FIG. 7. Isothermal $\mathrm{M}(\mathrm{H})$ curves in the vicinity of the magnetostructural phase transitions. 


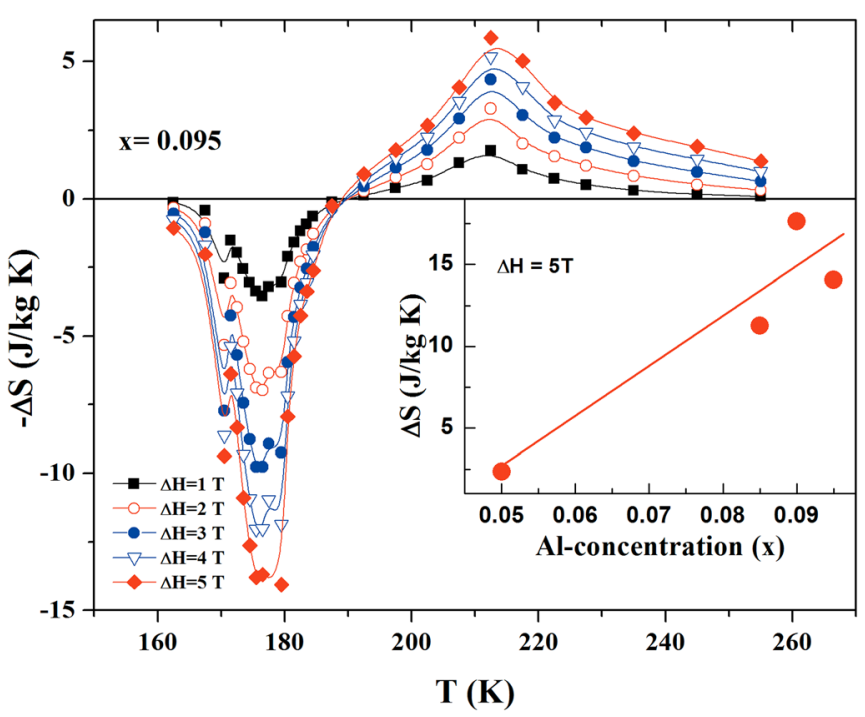

FIG. 8. The characteristic entropy changes in the vicinity of the magnetostructural transition at different applied fields, as shown for $\mathrm{MnNi}\left(\mathrm{Ge}_{0.905} \mathrm{Al}_{0.095}\right)$. Inset: The entropy changes obtained for $\Delta \mathrm{H}=5 \mathrm{~T}$ with respect to $\mathrm{Al}$ concentration $(\mathrm{x})$.

The change in the magnetic behavior in the vicinity of magnetostrucstural transitions from orthorhombic antiferromagnetic to hexagonal ferromagnetic and from orthorhombic antiferromagnetic to hexagonal paramagnetic phases are shown in Figures 7(a) and 7(b), respectively. As shown in Fig. 7(a), the magnetization curves show a gradual transition to ferromagnetism starting at $172-178 \mathrm{~K}$ and are associated with a field-induced reverse martensitic transformation. The magnetic entropy changes $\left(\Delta \mathrm{S}_{\mathrm{M}}\right)$ were calculated using the Maxwell relation, $(\partial \mathrm{S} / \partial \mathrm{H})_{\mathrm{T}}=(\partial \mathrm{M} / \partial \mathrm{T})_{\mathrm{H}}$, from the magnetization isotherms measured at different temperatures. ${ }^{18}$ The $\Delta \mathrm{S}_{\mathrm{M}}(\mathrm{T})$ curves for different changes in magnetic field $(\Delta \mathrm{H})$ are shown in Figure 8. A large inverse MCE has been observed in the vicinity of $\mathrm{T}_{\mathrm{M}}$, which is associated with the rapid change of magnetization (see Figure 3) due to the AF-FM first-order magnetostructural transition.

\section{CONCLUSION}

We have studied the influence of the partial substitution of $\mathrm{Ge}$ by $\mathrm{Al}$ on the magnetostructural and magnetocaloric properties of $\mathrm{MnNiGe}$. An Al-concentration-dependent phase diagram has been constructed to elucidate the magnet$\mathrm{ic} / \mathrm{magnetostructural}$ properties of the materials and to summarize the different types of magnetic/magnetostructural transitions observed in this system. For small Al concentrations $(x \leq 0.03)$, the system exhibits a PM-AFM, second order transition in a low-temperature orthorhombic phase with decreasing temperature. However, the substitution of higher $\mathrm{Al}$ concentrations results in a SOT from a FM to a PM state in its high-temperature hexagonal phase before showing a MST from an AFM to a FM state in the intermediate composition range $(0.085 \leq \mathrm{x} \leq 0.095)$. The MST from an AFM to a FM state results in a large inverse MCE in the vicinity of $T_{M}$ for compounds with $\mathrm{x}=0.085,0.090$, and 0.095. In general, the $\mathrm{MnNiGe}_{1-\mathrm{x}} \mathrm{Al}_{\mathrm{x}}$ compounds undergo remarkable changes in their magnetic properties and exhibit magnetostructural transitions which make them of interest due to their potential application in magnetic refrigeration.

\section{ACKNOWLEDGMENTS}

This work was supported by the Office of Basic Energy Sciences, Material Science Division of the U.S. Department of Energy (DOE Grant Nos. DE-FG02-06ER46291 and DEFG02-13ER46946). J.Y.C. acknowledges support from the National Science Foundation (NSF-DMR 1063735).

${ }^{1}$ A. O. Pecharsky, K. A. Gschneidner, Jr., and V. K. Pecharsky, J. Appl. Phys. 93, 4722 (2003).

${ }^{2}$ O. Tegus, E. Bruck, K. H. J. Buschow, and F. R. de Boer, Nature (London) 415, 150 (2002).

${ }^{3}$ T. Krenke, E. Duman, M. Acet, E. F. Wassermann, X. Moya, L. Mañosa, and A. Planes, Nat. Mater. 4, 450 (2005).

${ }^{4}$ S. Y. Yu, Z. H. Liu, G. D. Liu, J. L. Chen, Z. X. Cao, G. H. Wu, B. Zhang, and X. X. Zhang, Appl. Phys. Lett. 89, 162503 (2006).

${ }^{5}$ R. Kainuma, Y. Imano, W. Ito, Y. Sutou, H. Morito, S. Okamoto, O. Kitakami, K. Oikawa, A. Fujita, T. Kanomata, and K. Ishida, Nature (London) 439, 957 (2006).

${ }^{6}$ W. Bazela, A. Szytuła, T. Todorović, Z. Tomkowicz, and A. Zieba, Phys. Status Solidi A 38, 721 (1976).

${ }^{7}$ C. L. Zhang, D. H. Wang, Q. Q. Cao, Z. D. Han, H. C. Xuan, and Y. W. Du, Appl. Phys. Lett. 93, 122505 (2008).

${ }^{8}$ C. Zhang, D. Wang, Q. Cao, S. Ma, H. Xuan, and Y. Du, J. Phys. D: Appl. Phys. 43, 205003 (2010).

${ }^{9}$ Z. C. Liang, W. D. Hui, C. Jian, W. T. Zhi, X. G. Xi, and Z. Chun, Chin. Phys. B 20, 097501 (2011).

${ }^{10}$ E. Liu, Y. Du, J. Chen, W. Wang, H. Zhang, and G. Wu, IEEE Trans. Magn. 47, 4041 (2011).

${ }^{11}$ J. T. Wang, D. S. Wang, C. F. Chen, O. Nashima, T. Kanomata, H. Mizuseki, and Y. Kawazoe, Appl. Phys. Lett. 89, 262504 (2006).

${ }^{12}$ T. Samanta, I. Dubenko, A. Quetz, S. Temple, S. Standler, and N. Ali, Appl. Phys. Lett. 100, 052404 (2012).

${ }^{13}$ P. Entel, V. D. Buchelnikov, V. V. Khovailo, A. T. Zayak, W. A. Adeagbo, M. E. Gruner, H. C. Herper, and E. F. Wassermann, "Modelling the phase diagram of magnetic shape memory Heusler alloys," J. Phys. D: Appl. Phys. 39, 865-889 (2006).

${ }^{14}$ E. K. Liu, W. Zhu, L. Feng, J. L. Chen, W. H. Wang, G. H. Wu1, H. Y. Liu, F. B. Meng, H. Z. Luo, and Y. X. Li, "Vacancy-tuned paramagnetic/ ferromagnetic martensitic transformation in $\mathrm{Mn}$-poor $\mathrm{Mn}_{1-\mathrm{x}} \mathrm{CoGe}$ alloys," EPL 91, 17003 (2010).

${ }^{15}$ A. Ayuela, J. Enkovaara, K. Ullako, and R. M. Neiminen, J. Phys. Condens. Matter 11, 2017 (1999).

${ }^{16}$ M. Khan, I. Dubenko, S. Stadler, and N. Ali, "Magnetic and structural phase transitions in Heusler type alloys $\mathrm{Ni}_{2} \mathrm{MnGa}_{1-\mathrm{x}} \mathrm{In}_{\mathrm{x}}$," J. Phys.: Condens. Matter 16, 5259-5266 (2004).

${ }^{17}$ R. Z. Levitin and A. S. Markosyan, "Itinerant Metamagnetism," Usp. Fiz. Nauk 155, 623-657 (1988); I. L. Gabelko, R. Z. Levitin, A. S. Markosyan, V. I. Silantiev, and V. V. Snegirev, "Itinerant metamagnetism and ferromagnetism in the $\mathrm{M}(\mathrm{Col}-, \mathrm{Al}$,$) , (M EY and Lu) systems: The effect of unit$ cell volume," Zh. Eksp. Teor. Fiz. 98, 2067-2073 (1990).

${ }^{18}$ K. A. Gschneidner, Jr., V. K. Pecharsky, and A. O. Tsokol, Rep. Prog. Phys. 68, 1479 (2005).

${ }^{19}$ A. Altomare, M. C. Burla, M. Camalli, G. L. Cascarano, C. Giacovazzo, A. Guagliardi, A. G. G. Moliterni, G. Polidori, and R. Spagna, "SIR97: A new tool for crystal structure determination and refinement," J. Appl. Crystallogr. 32, 115-119 (1999).

${ }^{20}$ G. Sheldrick, "A short history of SHELX," Acta Crystallogr. A 64, 112-122 (2008). 